Agriculture 2011, 1, 1-3; doi:10.3390/agriculture1010001

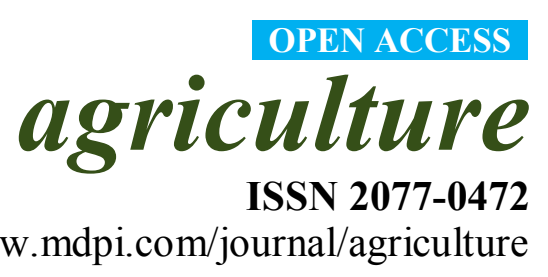

Editorial

\title{
Meeting the Challenges for Agriculture
}

\section{Les Copeland}

Founding Editor-in-Chief of Agriculture, Faculty of Agriculture, Food and Natural Resources, University of Sydney, NSW 2006, Australia; E-Mail: les.copeland@sydney.edu.au;

Tel.: +6128627 1017

Received: 6 June 2011 / Accepted: 8 June 2011 / Published: 8 June 2011

Ensuring food security is an ongoing global challenge. Many forecasts point to a need to increase food production by at least $70 \%$ if we are to feed the world's projected population of nine billion in 2050. Recent volatility in commodity prices and the general upward trend in the cost of food are indicators that global food systems are now driven by demand rather than supply. There are various reasons for this: greater demand for animal protein with economic growth in developing countries; the continuing increase in world population; competition between food and bioenergy crops for land and water; low inventories of world grain stocks; reduced investment in agricultural R\&D; and unfavorable weather resulting in a succession of poor harvests around the world. Increasing production of grains, which are the foundation of the human food supply, will have to be achieved through higher crop yields without boosting inputs of land, water and energy. Meeting community expectations for environmental stewardship and sustainability, and adapting food production to increasingly variable climate, add greatly to the challenge.

A related issue for agriculture is the production of foods that deliver health benefits to consumers. Diet-related diseases are widespread and costly: over one billion people suffer hunger, and double that number experience micronutrient deficiencies. Poor nutrition in infancy increases the susceptibility to chronic illness in later life. On the other hand, the number of people who consume an unhealthy excess of food now exceeds those who are hungry, increasing the incidence of largely preventable conditions such as obesity and diet-related cardiovascular disease, type 2 diabetes and certain types of cancers. By exerting small effects on many targets, food systems are a proactive and cost effective approach to managing and reducing the risk of diet-related illnesses.

The farm-dependent sector is a platform for economic development and a major contributor to the economy of most countries. The agriculture value chain incorporates on-farm production, management of water, soil and landscapes, postharvest handling and processing, quality and safety of products, and marketing and trade. As consumers of the end products, we are all engaged with agriculture. The logistics of contemporary supply chains are affected by global and local factors that influence the way 
food is presented to consumers. Population demographics, modern lifestyles, consolidation of enterprises, and the time and distance between food production and consumption, have increased the demand for processed foods and foods with longer shelf life. Hence, meeting the challenges of food security and achieving better health outcomes is not just a matter of increasing yield and ensuring that produce is fit for purpose; it will require innovations throughout the agriculture value chain.

What are the critical factors for success? Increases in yield and quality, and better management of natural resources, are driven by discovery and adoption of new technology. Since humans began cultivating crops and raising livestock thousands of years ago, productivity gains have resulted from a combination of advancing the genetics through selective breeding and adoption of better farming and post-farm practices. The continual progression of new varieties with increased tolerance to biotic and abiotic stress, better water and nutrient use efficiency, and better quality and nutritional attributes, coupled with concurrent advances in management of land, water, pests, weeds, and diseases, and better use of raw materials, have allowed food production to keep pace with demand through the ages. There are still many important knowledge gaps in our understanding of the agriculture resource base - the biology, the soil, and water and nutrient cycles in landscapes. Filling these gaps will lead to a better understanding of the complexities of agroecosystems and of the genetic potential of food plants and animals, how that potential is expressed, and how expression is influenced by environmental conditions. Developing and maintaining rural infrastructure for transport, storage and communications, particularly in developing countries, and policy settings that encourage profitability from efficiency gains, will also be important to boosting food production.

Lessons from history teach us that advances are more often incremental and come from making timely connections between existing knowledge in different disciplines. The success of the Green Revolution of the 1960s, and more recently, the adoption of conservation farming and precision agriculture, are examples of the benefits of integrating knowledge from multiple disciplines. Information rich technologies, such as global positioning systems, remote sensing, digital soil mapping, controlled traffic, variable rate technologies, coupled with biotechnology and bioinformatics, are the new tools to underpin agricultural growth. But not all gains will be in intensive agricultural systems or require complex technology. Improvements in smallholder agriculture will be important in many parts of the world. For example, simple measures such as making available clean planting materials can significantly increase yields of clonally propagated crops. Nor will all of the strategies for success be technological: applying principles of risk management and understanding the human element in adaptation to change will also be important.

I am delighted to introduce Agriculture, a scholarly, open access journal that will address these issues. Agriculture will publish high quality reviews, research papers, communications and short notes, reflecting the breadth of the agriculture value chain from an international perspective. Submissions are welcome in subject areas relevant to the aims and scope of the journal, including the science of cultivating the soil, growing and harvesting crops, raising livestock, the impact of climate on agroecosystems, processing of plant and animal products, and quality, marketing and use of foods and fibers.

There is no restriction on the length of the papers; our aim is to encourage scientists to publish their experimental and theoretical research in as much detail as possible. Full experimental and/or methodical details must be provided for research articles. All contributions submitted for publication in 
Agriculture are subject to rigorous peer review. The journal seeks to maintain a quick peer-review and publication process, usually within 4-8 weeks from submission, provided that no major revisions are required. Once accepted, articles will be published immediately and are freely available to readers on the Internet without any subscription or price barriers. Authors retain all copyright and the right of re-use, subject to proper attribution.

I look forward to helping establish Agriculture as a journal of choice for the publication of high quality research on the many aspects of agriculture.

(C) 2011 by the authors; licensee MDPI, Basel, Switzerland. This article is an open access article distributed under the terms and conditions of the Creative Commons Attribution license (http://creativecommons.org/licenses/by/3.0/). 